\title{
UM BREVE OLHAR SOBRE A CIENCIOMETRIA: Origem, Evolução, Tendências e sua Contribuição para o Ensino de Ciências
}

\author{
Maurício Rodrigues Parra ${ }^{1}$ \\ Renato Xavier Coutinho² \\ Edward Frederico Castro Pessano ${ }^{3}$
}

\begin{abstract}
RESUMO
O presente trabalho faz uma análise contextualizada a partir de um estudo bibliográfico sobre a Cienciometria, a qual se caracteriza como um novo ramo da ciência definida como o estudo da mensuração e quantificação do progresso científico, em que a pesquisa baseia-se em indicadores bibliométricos. Nesse cenário esta pesquisa tem como intuito percorrer a história, desvelando a possível origem da Cienciometria, seu desenvolvimento no mundo e no Brasil e ao final indicar possíveis tendências. A metodologia de sua execução caracteriza-se por um estudo de revisão bibliográfica sobre a referida temática, visando a localizá-la e diferenciá-la na Ciência da Informação junto com os demais ramos da ciência de mensuração, como a Bibliometria, a Informetria e a Webometria. As análises e discussões proporcionaram a verificação da necessidade do surgimento da Cienciometria dentro do cenário mundial, bem como a sua importância para com a avaliação da produção científica, fornecendo indicadores e subsídios para a comunidade acadêmica e sociedade em geral, pois, além de apontar para possíveis problemáticas relacionadas ao modelo quantitativo, indica as soluções para se observar a realidade social do pesquisador ou da pesquisa e também contribuir para a visualização de lacunas e de temáticas que são pouco investigadas. Palavras-chave: Cienciometria. Ciência da informação. Indicadores cienciométricos. Pesquisa quantitativa.
\end{abstract}

A BRIEF LOOK FOR SCIENTOMETRICS:

ORIGIN, EVOLUTION, TRENDS AND CONTRIBUTION FOR TO SCIENCE TEACHING

\begin{abstract}
This work makes a contextualized analysis from a bibliographical study on Scientometry, which is characterized as a new branch of science, defined as the study of the measurement and quantification of science progress, where research is based in bibliometric indicators. In this case, the present work aims go through the history, revealing the possible origin of Scientometry, its development in the world, in Brazil, and at the end indicating possible trends. The methodology of execution of this work is characterized by a bibliographical review study on the said subject, aiming to locate it and differentiate it in Information Science, along with the other branches of measurement science as Bibliometrics, Informetrics and Webometry. The analyzes and discussions provided the verification of the need for the emergence of Scientometrics within the world scenario, as well as its importance for the evaluation of scientific production, providing indicators and subsidies for academic community and society in general, beside pointing out possible problems related to the quantitative model, it indicates the solutions to observe the social reality of the researcher, or of the research, and also contributing to the visualization of gaps and themes that are little investigated.
\end{abstract}

Keywords: Scientometry. Information Science. Scientometric indicators. Quantitative research.

RECEBIDO EM: 8/9/2017

ACEITO EM: 10/9/2018

\footnotetext{
${ }^{1}$ Licenciado em Ciências Biológicas. Mestrando do PPG Educação em Ciências da UFSM. http://lattes.cnpq.br/2427953243602951. Orcid: https://orcid.org/0000-0002-2158-1946. parramau@gmail.com

${ }^{2}$ Licenciado em Educação Física. Mestre e doutor em Educação em Ciências. http://lattes.cnpq.br/4542170364363130. http://orcid. org/0000-0001-6602-2120. renato.coutinho@iffarroupilha.com

${ }^{3}$ Licenciado em Ciências Biológicas - PUCRS. Doutor em Educação em Ciências - UFSM. Professor do Curso de Ciências da Natureza - Unipampa. http://lattes.cnpq.br/2760002240063004. https://orcid.org/0000-0002-6322-6416. edwpessano@yahoo.com.br
} 
O presente trabalho faz um olhar sobre a Cienciometria, a partir de uma revisão bibliográfica, partindo da sua origem dentro da Ciência da Informação, a qual engloba um grande grupo, no qual também se encontram a Bibliometria, a Informetria e a Webometria. Dessa forma, o trabalho efetua uma breve revisão da conceituação desses ramos da Ciência da Informação e a partir desse ponto aprofunda-se na sistemática do trabalho que trata a Cienciometria. Para tanto realiza uma análise histórica dessa área, buscando traçar aspectos sobre a sua origem no mundo científico, motivos, conceitos e evolução, objetivando evidenciar como e quando a Cienciometria se insere no Brasil e sua importância para a educação.

Segundo alguns autores (TEIXEIRA; MEGID NETO, 2006), a avaliação dos conhecimentos acumulados é uma necessidade premente para qualquer setor de pesquisa, pois a partir deste conhecimento produzido pode-se inferir sobre novas áreas de investigação, apontando caminhos a serem percorridos. Neste sentido, Soares (1989) e Dávila (2012) salientam que a compreensão do estado de conhecimento sobre um tema, em determinado período, é de grande importância para o processo de compreensão da evolução da ciência, contribuindo para que se ordene periodicamente o conjunto de informações e resultados já produzidos. Dessa forma, permite-se a indicação das possibilidades de articulação e integração de diferentes perspectivas, que em um primeiro momento se apresentavam autônomas, bem como possibilitando a identificação de contradições e a determinação de lacunas.

Neste cenário Fracalanza (1993) manifesta que os estudos do tipo "Estado da Arte" podem constituir um banco de dados regular, que quando periodicamente atualizado serve de orientação para pesquisadores, estudiosos e demais interessados em uma determinada área, contribuindo para o avanço da ciência.

Ressalta-se que entre os objetivos da ciência está a busca por respostas, a investigação, a descoberta, a construção de novos conhecimentos, e o pesquisador acaba tendo como dever divulgar, difundir os resultados do seu trabalho. Assim surge a máxima: "A ciência que não é publicada não existe" (VESSURI apud VELHO, 1997). Essa forte indicação salienta a importância de se dar publicidade aos conhecimentos produzidos pela ciência e para os vetores de publicização dos dados, como periódicos e eventos científicos.

Segundo Velho (1997), só após tornar-se pública a produção acadêmica poderá demonstrar o seu valor, devendo ser difundida não apenas entre os pares do meio científico, mas também para o restante da sociedade. $O$ autor manifesta ainda, que a partir da difusão da sua produção é que o pesquisador poderá receber o devido reconhecimento pelo seu trabalho. A partir dessa constante geração de novos conhecimentos, contudo, é fundamental que seja avaliada toda essa produção, sua qualidade e o quanto está transpassando os "muros" da academia, alcançando a sociedade em geral e atingindo seus objetivos.

Segundo Seracevic (1996), a Biblioteconomia, caracterizada pela organização e preservação dos registros gráficos humanos, tem uma longa e orgulhosa história, remontando a 3 mil anos, contudo o mesmo autor salienta que a Ciência da Informação moderna surge no contexto da Segunda Guerra Mundial e evolui posteriormente, e a partir dos anos 60 toma outros formatos. Dessa forma, a Cienciometria pode ter surgido 
em países e regiões da Europa, como a Holanda, o Reino Unido e na antiga União Soviética, onde a avaliação da produção científica ocorre de forma pioneira, mas inicialmente voltada para fins de gestão administrativa e de organização da informação produzida.

No Brasil, esse foco da ciência surge sequencialmente, muito provavelmente, pois a pesquisa como um todo teve seu grande desenvolvimento apenas nos últimos 50 anos, devido às políticas públicas, com agências e instituições de fomento, instituídas a partir da década de 60. Nesse período, o governo federal começou a financiar projetos de pesquisas, programas de Pós-Graduação, eventos científicos e também promoveu mediante incentivos fiscais a participação do setor privado nesse objetivo.

Dessa forma, esse grande salto da produção científica gerou muita informação disponível, mas nem tanto organizada, fazendo-se necessário um trabalho de avaliação e organização da produção existente e esse diagnóstico pode ser obtido por meio de métodos quantitativos, que transformam as informações em números e estes em dados estatísticos. Nesse cenário, o Brasil passa também a mensurar a ciência produzida, fenômeno que se fortalece apenas a partir dos anos 90 segundo Quandt et al. (2009).

A produção intelectual e sistematizada é vista por Lourenço (1997) como uma produção documental sobre uma determinada área ou assunto de interesse de uma comunidade acadêmica específica, que contribui para o desenvolvimento da ciência e para a abertura de novos horizontes. Já Menezes (1993) a define como o arcabouço de investigações realizados por pesquisadores de variadas áreas, que geram conhecimentos aceitos pela comunidade científica, e seus resultados podem ser divulgados em veículos de comunicação formal, informal e não convencional.

Essa quantificação, análise e avaliação da ciência por meio de seus resultados, ou dos pesquisadores e instituições, pode ter seu produto demonstrado de inúmeras formas, como destaca Hayashi (2013) no seu trabalho. Segundo o autor, as investigações voltadas ao Estado da Arte são baseadas principalmente no interesse em caracterizar a produção e a produtividade científicas, destacando-se que os estudos métricos da informação estão associados ao campo da Ciência da Informação e suas origens podem ser buscadas no campo da Sociologia da Ciência.

Nesse contexto, o presente trabalho visa a contribuir com as definições do termo Cienciometria na perspectiva de vários estudiosos do tema e sua aplicabilidade e relevância tanto para a comunidade científica quanto para a sociedade em geral, evidenciando possíveis problemas e potencialidades do uso dessa ciência. Esta investigação visa ainda, a efetuar uma breve análise das pesquisas em Cienciometria no Brasil, percorrendo a sua história, desvelando suas origens, sua importância dentro da educação, seu desenvolvimento e ao final indicar possíveis tendências de estudo. Assim sendo, este estudo pretende contribuir para disseminar e dar visibilidade para pesquisas e relatos de experiências relacionados à educação em Ciência da Informação.

\section{ASPECTOS METODOLÓGICOS}

O presente trabalho foi elaborado no primeiro semestre de 2017. A metodologia desenvolvida por esta investigação consistiu em um levantamento do tema Cienciometria e demais conceitos afins relacionados à Ciência da Informação. 
Para tanto elaborou-se uma revisão bibliográfica, principalmente por meio de publicações contidas em bancos de dados disponíveis em meio eletrônico na Internet, como o Portal de Periódicos Capes e Scielo, sites de instituições de ensino, Google Acadêmico e também em livros, revistas e anais de eventos relacionados a essa área de investigação. Nesse sentido, para avaliar essa área da ciência crescente no Brasil, efetuamos uma busca no Google Acadêmico e no Banco de Dados da Capes, objetivando detectar o número de trabalhos que versavam sobre os termos: Cienciometria e Cientometria nos últimos 10 anos. Utilizou-se também o termo Cientometria por ser considerado um sinônimo de Cienciometria.

Segundo Richardson (1989), esse método utilizado caracteriza-se como bibliográfico e exploratório, por meio do emprego da quantificação, tanto nas modalidades de coleta de informações quanto no seu tratamento, por meio de técnicas estatísticas, as quais transformam em números os dados para serem classificados e analisados.

\section{INFORMAÇÕES, ANÁLISES E DISCUSSÕES}

\section{Origem da Cienciometria}

Existem muitas controvérsias a respeito de onde surgiu o termo Cienciometria, mas provavelmente na Europa, com a antiga União Soviética sendo a principal alternativa, mas a maioria sugere o nome do inglês Derek John de Solla Price como o pai da Cienciometria. Price foi um físico, historiador da ciência e cientista da informação. Para desenvolver sua metodologia, segundo Santos e Kobashi (2009), Price utilizou-se "das propostas de Lotka, Bradford e Zipf para formular suas leis cienciométricas; os estudos quantitativos adquiriram novos contornos, centrando-se, fundamentalmente, na análise da dinâmica da atividade científica, incluindo tanto os produtos quanto os produtores de ciência".

Assim, conforme descrito pelo próprio Price (1963), o crescimento exponencial da informação científica produziu impactos na análise da enorme quantidade de textos científicos disponíveis, e para isso foi necessário aplicar técnicas estatísticas aos escritos científicos.

A Cienciometria nasce, portanto, como a conhecemos hoje, a partir dos anos 60 do século 20, do cruzamento da documentação científica, da Sociologia da Ciência e da História Social da Ciência, com a finalidade de investigar a atividade científica como fenômeno humano, social e mediante parâmetros e indicadores baseados em modelos matemáticos.

A Cienciometria é popularmente denominada no meio acadêmico de "a ciência da ciência" e segundo Courtial (1993), a ciência da ciência conduziu à elaboração de um novo embrião da Bibliometria, que reuniu pesquisadores dos países capitalistas e dos países marxistas, a partir dos anos 70 .

\section{Evolução e Definição da Ciencimentria}

A Cienciometria, por se tratar de pesquisa quantitativa, centra-se na objetividade. Sendo assim, é influenciada pelo positivismo, considerando que a realidade só pode ser compreendida a partir da análise de dados brutos, obtidos com o auxílio de instrumentos padronizados e neutros, conforme menciona Fonseca (2002). 
Para Vanti (2002), as técnicas quantitativas de avaliação da informação atualmente podem dividir-se em quatro áreas principais: a Bibliometria, a Cienciometria, a Informetria e a Webometria. Segundo o mesmo autor, todas elas se propõem a medir a propagação do conhecimento científico e o fluxo da informação sobre diferentes aspectos e enfoques. Nesse contexto, todas as áreas baseiam-se no fato de que a essência da pesquisa é a produção do conhecimento e que a literatura científica é um desses componentes (MACIAS-CHAPULA, 1998).

Essas áreas da Ciência da Informação utilizam métodos alicerçados na utilização de técnicas estatísticas e também na aplicação da Matemática à Sociologia, considerando em caráter especial o resultado de contagens e medições (GOODE; HATT, 1969).

Hayashi (2013) manifesta que a Ciência da Informação se constitui como um campo interdisciplinar que se dedica à investigação quantitativa da ciência e também da tecnologia, estando voltada para a avaliação da produção científica e tecnológica elaborada pela comunidade científica, em diferentes áreas do conhecimento.

Devemos ressaltar que embora a Bibliometria, a Cienciometria, a Informetria e Webometria possuam em sua essência as mesmas bases e princípios, elas se voltam a campos específicos e com objetivos diferentes, os quais serão devidamente analisados por este trabalho.

A Bibliometria é definida por Pritchard (1969) como um conjunto de métodos e técnicas quantitativos para a gestão de bibliotecas e instituições envolvidas com o tratamento de informação. Trata-se, portanto, de um campo da ciência fundamentado em uma técnica quantitativa, que visa a transformar em dados estatísticos os índices do produto científico registrado e na sua disseminação. Seus principais objetos de trabalho são os livros, revistas, documentos, autores, usuários; tenta ranquear, definir a frequência de acessos e o uso destes, conseguindo assim um melhor uso deles.

A Cienciometria de acordo com Goode e Hatt (1969) e por Hayashi (2013), foca-se na avaliação da produção científica e não se baseia em textos e trabalhos não científicos ou empíricos, centrando-se na mensuração da ciência.

Ainda conforme Hayashi, pode ser caracterizada como:

... campo interdisciplinar dedicado ao estudo quantitativo da ciência e da tecnologia e estão voltados para avaliar a produção científica e tecnológica produzida pela comunidade científica no interior das áreas de conhecimento (Hayashi, 2013, p. 2).

A Webometria é outra área de mensuração da ciência e que merece nosso destaque. Web é o termo como a rede mundial de computadores ficou conhecida, portanto o campo de trabalho da Webometria é a Internet e todas as suas ferramentas, como links, hipermídias, domínios, URLs, portais, sites, páginas, aplicativos de busca, etc. Segundo os autores Almind e Ingwersen (1997), a "Webometria consiste na aplicação de métodos infométricos à World Wide Web."

A Webometria é um ramo novo de pesquisa, pouco estudado, que vem ganhando importância devido à popularização e importância, principalmente financeira, que a Internet possui atualmente. A Webometria busca fazer a metria, ou seja, a mensuração 
das informações na Rede Mundial de Computadores por meio do fluxo de dados acessados e disponíveis, principalmente nos grandes portais de pesquisa. Nesse sentido, busca a partir de abordagens infométricas e bibliométricas analisar o fluxo de informação na rede.

Em relação à Informetria, contudo, segundo Macias-Chapula (1998), trata-se do estudo e investigação dos aspectos e bases quantitativas da informação, em diferentes mídias e formatos, não se baseando apenas em registros catalográficos ou em bibliografias e pode-se referir a qualquer grupo social, e não apenas aos cientistas.

Assim, e de acordo com Wormell (1998), “... a Informetria é um subcampo emergente da Ciência da Informação, baseada na combinação de técnicas avançadas de recuperação da informação com estudos quantitativos dos fluxos da informação". Ou seja, como já salientado, trata-se da quantificação da informação em qualquer formato, e não apenas em registros catalográficos ou bibliografias (MACIAS-CHAPULA, 1998).

Dessa forma, também faz uso de técnicas estatísticas e, ainda, da aplicação da Matemática para a Sociologia. Abrange, assim, um campo muito maior, pois engloba a Bibliometria, a Cienciometria e a Webometria, tentando relacioná-las com as demais ciências e indo além do meio científico, chegando até o universo da Internet, visando a um melhor aproveitamento da informação, um acesso mais eficiente e sugestão de temas relacionados ao interesse da busca.

A quarta subdivisão que se faz da Ciência da Informação é o tema norteador desse trabalho, a Cienciometria, a qual já foi mencionada sucintamente anteriormente, mas que a partir desse ponto será aprofundado o debate sobre essa metodologia de pesquisa.

De acordo com Macias-Chapula (1998, p. 134), a Cienciometria consiste em:

Um estudo dos aspectos quantitativos da ciência enquanto uma disciplina ou atividade econômica. A Cienciometria é um segmento da sociologia da ciência, sendo aplicada no desenvolvimento de políticas científicas. Envolve estudos quantitativos das atividades científicas, incluindo a publicação.

A Cienciometria também pode ser encontrada pela denominação de Cientometria, pertencente à Sociologia das Ciências e da Ciência da Informação, a qual busca quantificar a evolução da ciência e da produção científica, seja no meio da pesquisa propriamente dita, seja nas possíveis influências no mercado econômico e na sociedade em geral. Segundo Velho (1990) e Spinak (1998), o estudo cienciométrico fundamenta-se em analisar a atividade científica por meio de técnicas matemáticas e estatísticas, desenvolvendo indicadores confiáveis, como parâmetros para avaliação e exploração dos dados.

Esse ramo de estudo da Ciência da Informação tem mostrado um papel relevante na análise da produção científica de um país, região, Estado, etc., revelando o grau de conhecimento de determinada área e contribuindo para o direcionamento de novas investigações. Um dos mecanismos utilizados para a disseminação dos resultados das pesquisas é a publicação de artigos em periódicos científicos, que segundo Silva (2004) é o meio mais utilizado. Sendo assim, é interessante avaliar quantitativamente os dados sobre produção científica, a fim de entender como se dão os processos de consolidação da ciência e como esse mecanismo está organizado. 
Ressalta-se que a preocupação com a avaliação cienciométrica eleva-se à medida que aumenta também a importância de dados e informações virtuais, principalmente por meio dos recentes avanços tecnológicos que permitem acesso à informação de artigos e mesmo aos próprios documentos (ALBERGUINI, 1999). Os resultados obtidos mediante essa avaliação são de grande relevância para diversas instituições, sejam públicas ou privadas, pois podem ilustrar os interesses, carências, saturações do seu mercado-alvo e indicar direcionamentos a partir das lacunas apontadas.

Esse processo, portanto, também se justifica devido às novas tecnologias e ao fácil acesso à informação, uma vez que em anos anteriores era necessário se deslocar para uma biblioteca ou banco de dados para se obter acesso à informação. Atualmente, com o advento da Internet e das bases de dados virtuais, a popularização da produção acadêmica proporciona a todos esse acesso, sem ao menos precisarem sair de casa.

Nesse cenário, ocorrem investimentos financeiros para essas ferramentas de busca, websites, portais, entre outras das várias ferramentas existentes, mas sempre que se trata de valores (dinheiro) o investidor quer o melhor para a sua marca ou projeto, nisso que os resultados obtidos serão de grande valia.

Para Callon, Courtial e Penan (1995), a Cienciometria aplica-se, principalmente, no tratamento e gerenciamento das informações formais provenientes de bases de dados científicas ou técnicas. Inclusive, segundo estes autores, as empresas utilizariam os métodos cienciométricos para conseguir determinar qual a estratégia tecnológica seguida por seus competidores e desta forma atuar sobre a produção e áreas de investimento.

\section{A Importância dos Indicadores Cienciométricos}

A Cienciometria faz uma avaliação do todo, e não dos resultados de cada trabalho, não entrando nesse mérito. Para a Cienciometria faz-se necessário uma sistematização dos métodos, abordagens, áreas, etc., a partir da quantificação do progresso científico. Para tanto são definidos previamente e estabelecidos os elementos e quesitos que nortearão o processo de investigação e mensuração. Esses elementos são denominados de Indicadores Cienciométricos.

A seguir estão elencados alguns exemplos desses indicadores:

- Número de trabalhos, coautorias, publicações do autor, instituição ou país

- Número de citações obtidas

- Número de patentes

- Número de artigos publicados

- Número médio de citações por artigo

- Fator de impacto

- Número de citações e nível da revista/periódico

- Potenciais e limitações da área investigada. 
Neste contexto e a partir dos diversos indicadores existentes, a Cienciometria pode resultar em dados possíveis de serem utilizados em variados programas, desde políticas públicas, até pela própria ciência, avaliando a evolução ou estagnação de um específico campo de pesquisa e também indicando a necessidade de investigação em determinado campo.

Cabe ressaltar que no atual cenário de crise política e econômica em que se encontra o Brasil, determinar a correta alocação de recursos para a produção da pesquisa é de suma importância, para que não haja um desperdício de dinheiro, tempo e pessoas, em áreas já amplamente investigadas, enquanto outras com grande potencial ficam deixadas de lado. Assim a Cienciometria ganha destaque e relevância.

Já no setor privado as grandes organizações estão sempre atentas a essa avaliação científica, que vai determinar onde estão as principais demandas do mercado e onde este já está saturado, e também em questões de patentes e de novos métodos, tecnologias de produção, entre outros, que poderão proporcionar avanços para a humanidade, gerando a possibilidade de grandes lucros para essas instituições.

Existem inúmeras formas de utilização das técnicas Cienciométricas, e segundo Spinak (1998), a importância pode ser vista analisando a seguinte lista de possíveis aplicações, a qual o autor ressalta que essa não pretende ser completa.

- Identificar tendências e crescimento do conhecimento em todas as disciplinas;

- Estimar a cobertura de revistas secundárias;

- Identificar usuários de diferentes disciplinas;

- Identificar autores e tendências em diferentes disciplinas;

- Medir a utilidade de disseminação seletiva de informações;

- Prever publicação tendências;

- Identificar revistas do núcleo em cada disciplina;

- Formular políticas ajustadas às aquisições de orçamento;

- Adaptar as políticas;

- Para estudar a dispersão e caducidade de literatura científica;

- Processos de design de indexação, classificação automática e fazer resumos;

- Prever editores de produtividade, etc.

A utilização desses indicadores e a forma de aplicação deve ser cuidadosa, pois podem levar a conclusões precipitadas, devendo-se levar em conta o contexto, a realidade e as peculiaridades de onde os dados são retirados. Geralmente dá-se muita importância para fatores objetivos e deixa-se de lado a realidade social do pesquisador, em que o número de publicações vale mais do que as atividades de ensino, que no Brasil é a principal competência dos professores no Ensino Superior.

Podemos destacar ainda que a Bibliometria e Cienciometria são áreas de Ciência da Informação bem próximas, especialmente pelo fato de ambas abordarem a produção de informação mais formal, científica. Na realidade podemos inferir que a Cienciometria surge da Bibliometria, e se completam, por meio da Cienciometria que engloba a própria Bibliometria. Nessa mesma linha de reflexão, a Informetria e a Webometria são segmentos bem mais amplos da produção de conhecimento, abordando todo tipo de informação e com isso englobando as demais. 
Em uma comparação direta pode-se afirmar que Bibliometria tem como objetos de estudo os livros, literatura, documentos ou as revistas científicas, cujas análises se vinculam à gestão de bibliotecas e bases de dados. Já a Cienciometria utiliza como objetos de suas análises a produção, principalmente artigos, a circulação e o consumo da produção científica, preocupando-se com a dinâmica da ciência, qual a sua utilidade científica e qual o impacto desse produto.

\section{A Cienciometria no Brasil e suas tendências}

No Brasil, os programas de Pós-Graduação começaram a ter relevância para as políticas de governo a partir dos anos 60 , ganhando um amparo legal na década seguinte, como apontam os autores Población e Noronha (2002, p. 98): "Os cursos de pós-graduação foram institucionalizados no Brasil, em 1970, com a Lei 5.540/68. Com o passar dos anos, os programas de pós-graduação tornaram-se o maior pólo gerador da produção científica brasileira".

Dessa forma, com a produção científica e a formação de profissionais em nível de Mestrado e Doutorado, a ciência brasileira apresentou um crescimento exponencial ao longo deste período, fazendo com que o Brasil atingisse em 2015 o primeiro lugar na América Latina e 23 no ranking global em produção científica (NATURE INDEX, 2015).

Nesse cenário, a principal ferramenta utilizada atualmente para quantificar e avaliar a produção científica e os pesquisadores no Brasil é a Plataforma Sucupira da Capes e o sistema Qualis da mesma Plataforma. O sistema Qualis está sob tutela da Coordenação de Aperfeiçoamento de Pessoal de Nível Superior (Capes), órgão vinculado ao MEC e busca classificar em categorias e conceitos as produções científicas, contribuindo para com a determinação de parâmetros de qualidade, que servem como referência para pesquisadores e Programas de Pós-Graduação. Este processo depende diretamente da produção científica dos pós-graduandos e orientadores, principalmente na forma de artigos científicos em periódicos e anais de eventos.

A respectiva importância desses veículos de comunicação dentro da comunidade científica também é avaliada regularmente, quando esses meios e mídias de difusão científica também são mensurados pelo seu impacto nas diferentes áreas do conhecimento. A troca dessas informações entre a Capes e os programas ocorre mediante uma ferramenta on-line, denominada de Plataforma Sucupira, que busca facilitar o acesso às informações, processos e transparência nos procedimentos da avaliação da Capes.

Sendo assim, no momento em que há uma consolidação da prática científica, com o aumento da produção de conhecimentos pela ciência, nas instituições de ensino e de pesquisa, é também fundamental a prática do uso de técnicas quantitativas e de mensuração de maneira a se complementarem. Neste cenário a Cienciometria ganha força, utilizando-se dessas metodologias quantitativas para sistematizar a ciência produzida. Destacamos, contudo, que para tanto também deveriam ser levadas em consideração as diferentes realidades sociais, já mencionadas anteriormente, obtendo-se assim uma análise mais precisa da realidade científica atual.

Conforme afirma Ferreira (2002):

O Brasil e outros países têm produzido um conjunto significativo de pesquisas conhecidas pela denominação "estado da arte" ou "estado do conhecimento". Estas pesquisas pretendem mapear e discutir a produção acadêmica em diferentes campos do conhecimento, tentando responder que aspectos e dimensões vêm sendo 
destacados e privilegiados em diferentes épocas e lugares, de que formas e em que condições têm sido produzidas certas dissertações de Mestrado, teses de Doutorado, publicações em periódicos e comunicações em anais de congressos e de seminários.

Posto isso e visando a avaliar essa crescente área da ciência no Brasil, efetuamos uma busca no Google Acadêmico e no Banco de Dados da Capes objetivando detectar os trabalhos que versavam sobre os termos Cienciometria e Cientometria nos últimos 10 anos. Utilizou-se também o termo Cientometria pelo fato de ser considerado um sinônimo de Cienciometria. Os dados encontrados produziram os resultados dispostos nos Quadros 1 e 2 e nas Figuras 1 e 2 a seguir.

Quadro 1 - Número de trabalhos encontrados no site de buscas Google Acadêmico, com o tema "Cienciometria e Cientometria", escritos em Português, por ano de produção, no período de 2006 até 2016

\begin{tabular}{|c|c|}
\hline \multicolumn{2}{|c|}{ Google Acadêmico - Cienciometria/Cientometria } \\
\hline Ano & Número de Trabalhos \\
\hline 2006 & 98 \\
\hline 2007 & 144 \\
\hline 2008 & 172 \\
\hline 2009 & 315 \\
\hline 2010 & 365 \\
\hline 2011 & 316 \\
\hline 2012 & 419 \\
\hline 2013 & 530 \\
\hline 2014 & 503 \\
\hline 2015 & 533 \\
\hline 2016 & 470 \\
\hline Total & 3.865 \\
\hline
\end{tabular}

Fonte: Dados encontrados pelos autores no Google Acadêmico.

Figura 1 - Gráfico demonstrativo referente à produção de trabalhos sobre Cienciometria e Cientometria a partir do site do Google Acadêmico entre os anos de 2006 e 2016

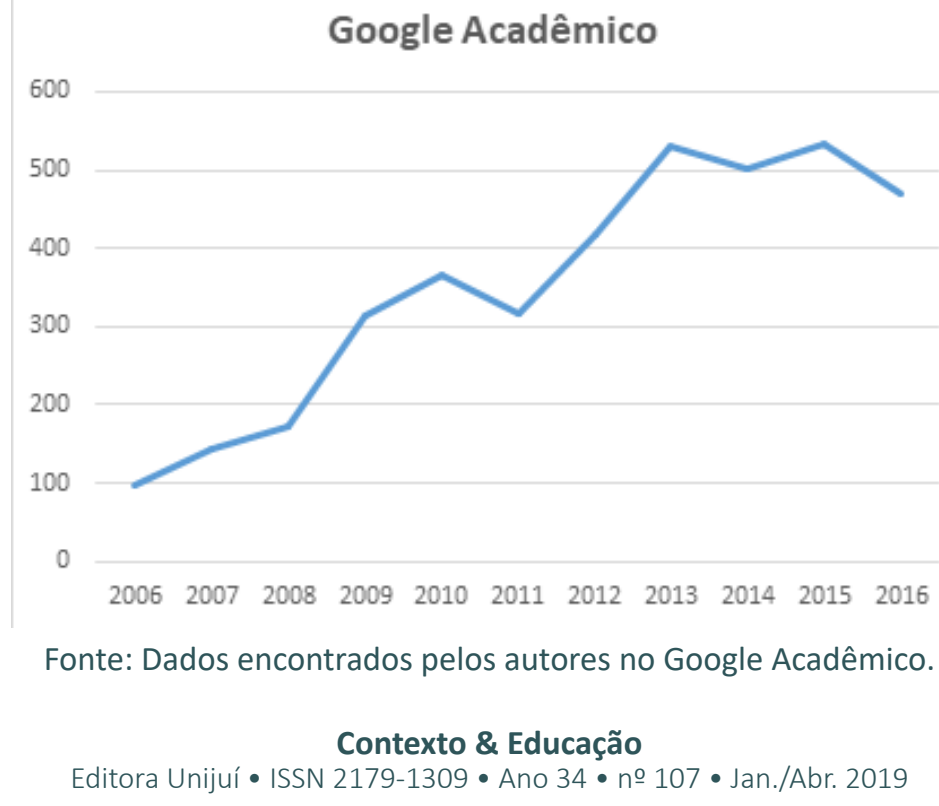


Quadro 2 - Número de trabalhos encontrados no portal Capes, com o tema "Cienciometria e

Cientometria", escritos em Português, por ano de produção, no período de 2006 até 2016

\begin{tabular}{|c|c|}
\hline \multicolumn{2}{|c|}{ Portal de Periódicos Capes - Cienciometria/Cientometria } \\
\hline Ano & Número de Trabalhos \\
\hline 2006 & 2 \\
\hline 2007 & 9 \\
\hline 2008 & 3 \\
\hline 2009 & 4 \\
\hline 2010 & 12 \\
\hline 2011 & 18 \\
\hline 2012 & 15 \\
\hline 2013 & 17 \\
\hline 2014 & 23 \\
\hline 2015 & 26 \\
\hline 2016 & 8 \\
\hline Total & 137 \\
\hline
\end{tabular}

Fonte: Dados encontrados pelos autores no portal Capes.

Figura 2-Gráfico demonstrativo referente à produção de trabalhos sobre Cienciometria e Cientometria a partir do site do portal Capes

\section{Portal Periódicos Capes}

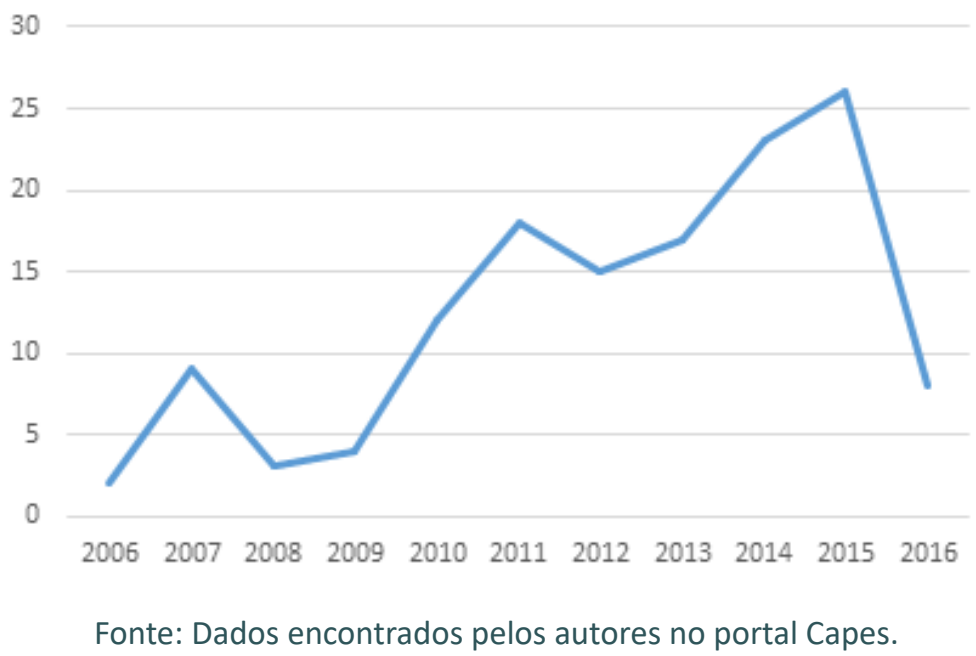

A partir dos dados encontrados e demonstrados nos Quadros e Figuras 1 e 2, percebe-se o aumento das produções relativas ao Estado da Arte denominadas como Cienciometria ou Cientometria. Salienta-se, portanto, a importância desta nova área da ciência, a qual tem como intuito medir a produção científica em diferentes áreas do conhecimento.

Os dados demonstram ainda um aumento com oscilações, merecendo destaque os resultados do Portal Capes para o ano de 2016, em que uma queda brusca de trabaIhos nessa área é constatada. 
Desse modo, pode-se inferir a partir dos resultados encontrados que anualmente a Ciência da Informação, especialmente a Cienciometria, vem ganhando espaço no cenário científico nacional. Isso revela a importância das investigações e da ciência em avaliar os seus próprios processos.

\section{A Cienciometria e a sua importância para o Ensino de Ciências}

No Brasil o ensino com pesquisa nos campos da Ciência da Informação, e mais especificadamente na Cienciometria, tem se intensificado nos últimos anos, fator que pode ser verificado no Portal de Periódicos da Capes e no site do Google Acadêmico, com produções em diferentes áreas da educação. Isso possui grande relevância para a produção de conhecimentos e aprimoramento dos processos de ensino. Gonçalves e Godinho (2014), que avaliaram a prática da pesquisa de estudantes a partir da competência informacional, apontam que a aquisição de conhecimentos, habilidades e atitudes requer do indivíduo uma postura receptiva a novas informações e tecnologias que possibilitem aos sujeitos a capacidade de discernimento para avaliar as informações. Neste sentido, a ciência da informação tem contribuído para isso, fornecendo os subsídios necessários para a sistematização e acesso às informações.

Dávila (2012) observa uma forte expansão da pesquisa em Educação em Ciências no final dos anos 90 e início de 2000, devido à ampliação do número de Programas de Pós-Graduação na área de Ensino de Ciências e Matemática. A intensificação da produção científica na área e a criação de programas de Mestrado e Doutorado com características próprias foi fator decisivo para que ocorresse, no ano de 2000, a instalação de um novo Comitê de Área na Capes - Coordenação de Aperfeiçoamento de Pessoal de Ensino Superior, o Comitê de Ensino de Ciências e Matemática (NARDI, 2005).

Segundo Razera (2016b), a área de pesquisa em Educação em Ciências no Brasil está consolidada. Não temos mais dúvidas sobre esse fato. São aproximadamente cinco décadas configuradas por uma curva crescente de produção científica. Diversas áreas brasileiras de conhecimento, incluindo a Educação, têm apresentado crescentes produções com interface cienciométrica (ARAÚJO; ALVARENGA, 2011). Ainda assim Razera (2016b) argumenta que a área de Educação em Ciências não está acompanhando e se aproveitando dessa tendência de crescimento. Não existem muitos relatos de pesquisa cienciométrica divulgados em nossos principais periódicos.

A área de Educação em Ciências no Brasil já está consolidada e merece ser conhecida com mais detalhes quantitativos de produção e de conteúdo. $O$ estudo cienciométrico é uma das opções para atingir esse objetivo (JESUS; RAZERA, 2013).

Nesse cenário, destaca-se também que nos diferentes níveis de ensino a busca pela informação tem aumentado devido às novas tecnologias de comunicação e facilidade de acesso à Internet. Esse fenômeno exige que a informação disponível seja confiável e de fácil acesso, fator que corrobora a importância da organização e sistematização das informações existentes e suas implicações na educação e no ensino.

Segundo Brito e Valls (2015), até a década de 90 as pesquisas escolares, por exemplo, eram feitas em fontes bibliográficas encontradas nas bibliotecas. Assim, explicam os autores que atualmente as fontes se diversificaram e que essa facilidade de acesso 
traz também a complexidade da busca, requerendo que o estudante possua competência para encontrar a informação. Sendo assim, a Ciência da Informação acaba por desempenhar um importante papel nos processos educacionais, atuando como uma ferramenta catalisadora pela busca de informações.

Dessa forma, salienta-se que revistas científicas, as quais são um dos principais meios de divulgação da ciência e dos novos conhecimentos produzidos, igualmente têm dado atenção para a sistematização de seus dados e oferta de informações organizadas, fatores que qualificam o periódico e proporcionam novos direcionamentos aos trabaIhos produzidos.

Outro aspecto a ser destacado é a avaliação dos periódicos quanto a critérios que determinam a sua qualidade na condição de difusores da informação. Um estudo realizado por Corrêa e Miranda (2016) buscou analisar se as revistas científicas de acesso aberto da área de Educação da região sul do Brasil atendiam aos critérios de qualidade sugeridos pela Scientific Electronic Library On-line (SciElo). Entre as suas conclusões, as autoras apontaram que a maior parte dos periódicos avaliados apresentava a credibilidade e a transparência necessárias para alcançar a excelência em qualidade de informação para com a comunidade científica, aproximando, desse modo, a Ciência da Informação dos processos de pesquisa e colaborando com a educação.

Enfim, ao analisar a manifestação de Cardoso (2002) em seu estudo, em que é apresentada uma síntese do Relatório Delors (2000) sobre a educação, este afirma que as novas gerações deverão apresentar quatro saberes fundamentais: aprender a aprender, aprender a fazer, aprender a ser e aprender a conviver. Saberes estes que demarcam um novo olhar sobre a função educativa, baseada na formação de sujeitos com competências e habilidades para enfrentar situações inesperadas, solucionar problemas e acompanhar o desenvolvimento do conhecimento.

No Brasil ainda existe uma lacuna de estudos cienciométricos sobre formação de professores em trabalhos publicados na área de Educação em Ciências (RAZERA, 2016a).

Nesse contexto, Cardoso (2002) cita ainda que a Ciência da Informação é intrínseca nesse processo, pois procura compreender seu objeto em seus múltiplos aspectos, de forma a possibilitar uma percepção menos fragmentada entre os diferentes campos da ciência e do conhecimento, estabelecendo interfaces e reconhecendo as singularidades de cada um.

A eficácia do trabalho do professor de Ciências está diretamente relacionada à capacidade de articular as práticas educativas às práticas sociais, ou seja, o trabalho desenvolvido nas escolas com o processo de democratização e reconstrução da sociedade (SAVIANI, 1997).

\section{CONSIDERAÇÕES FINAIS}

Realizamos com esse estudo uma breve contextualização da Cienciometria dentro do campo da Ciência da informação e da pesquisa quantitativa com foco no Ensino de Ciências. Partimos desde a sua origem até atuais aplicações, com a sua consolidação nas últimas décadas motivada pela grande produção científica. Fator que enaltece a sua importância em medir e mensurar a produção e também os próprios pesquisadores, 
gerando assim dados plausíveis para serem utilizados tanto pela comunidade científica quanto pela sociedade em geral, colaborando com variadas áreas do conhecimento, especialmente com a educação e seus processos de ensino.

Ao percorrermos essa trajetória apontamos os possíveis problemas com a validação dos dados caso não ocorra uma associação com a realidade, tanto do pesquisador quanto de onde são retiradas as informações que alimentam a pesquisa quantitativa, posto que o contexto social e econômico pode interferir no real significado dos dados encontrados.

Ressaltamos, portanto, que as instituições públicas e as organizações privadas devem fomentar ainda mais essa área da ciência e colocar em prática a racionalização dos conhecimentos que estão sendo gerados, pois a partir de um mapeamento fornecido pela Cienciometria poderemos aferir valores e consequentemente qualificar o processo, proporcionando diretrizes e apontando caminhos adequados e eficientes, permitindo, assim, que a humanidade evolua como um todo.

\section{REFERÊNCIAS}

ALBERGUINI, A. Coleções de artigos científicos na Internet. Newsletter LabJor, Campinas, v. 5, n. 11, p. 7-15, 1999.

ALMIND, T. C.; INGWERSEN, P. Informetric analyses on the world wide web: methodological approaches to "webmetrocs". Journal of Documentation, Bingley United Kingdom, v. 53, n. 4, p. 404-426, 1997.

ARAÚJO, R. F.; ALVARENGA, L. A bibliometria na pesquisa científica da pós-graduação brasileira de 1987 a 2007. Encontros Bibli: Revista Eletrônica de Biblioteconomia e Ciência da Informação, Florianópolis, v. 16, n. 31, p. 51-70, 2011. Disponível em: http://dx.doi.org/10.5007/1518-2924.2011v16n31p51. Acesso em: 18 jun. 2017.

BRITO, R. G.; VALLS, V. M. Novas formas de aprendizagem e a mediação da informação: competências necessárias aos bibliotecários. Rev. Brasileira de Educação em Ciência da Informação, v. 2, n. 1, p. 3-28, 2015.CALLON, M.; COURTIAL, J.-P.; PENAN, H. La scientométrie. Paris: PUF, 1993.

CALLON, M.; COURTIAL, J. P.; PENAN, H. (org.) Cienciometría: La Medición de la Actividad Científica, de la Bibliometría a la Vigilancia Tecnológica. Gijón: Trea, 1995. 110p.

CARDOSO, A. M. P. Educação para a informação: desafios contemporâneos para a Ciência da Informação. Revista de Ciência da Informação, v. 3, n. 5, p. 1-8, 2002.

CORRÊA, T. P. P.; MIRANDA, A. C. D. Critérios de qualidade em revistas científicas de acesso aberto em educação da região sul do Brasil. Rev. Brasileira de

Educação em Ciência da Informação, v. 3, n. 2, p. 51-66, 2016.

COURTIAL, J. P. L'Association pour la Mesure des Sciences et des Techniques et l'évaluation de la recherché en France. La Revue pour l'Histoire du CNRS, Paris, v. 9, n. 3, 2003.

DÁVILA, E. da S. Análise das dissertações e teses dos PPGs da área do ensino de ciências e matemática do $R S$ - 2000 a 2011. 2012. 62f. Dissertação (Mestrado) - UFSM, Programa de Pós-Graduação em Educação em Ciências da Universidade Federal de Santa Maria, Santa Maria, RS, 2012.

DELORS, J. (org.). Educação: um tesouro a descobrir. São Paulo: Cortez; Brasília: MEC; Unesco, 2000.

FERREIRA, N. S. A. As pesquisas denominadas "estado da arte". Educação \& Sociedade, Campinas, n. 79, p. 257-272, 2002.

FONSECA, J. J. S. Metodologia da pesquisa científica. Fortaleza: UEC, 2002. 123p.

FRACALANZA, H.; AMARAL, I. A.; MEGID NETO, J.; EBERLIN, T. S. A educação ambiental no Brasil: Panorama inicial para a produção acadêmica. In: ENCONTRO DE PESQUISA EM EDUCAÇÃO EM CIÊNCIAS, 2005, Bauru: Abrapec, 2005. Disponível em: http://www.nutes.ufrj.br/abrapec/venpec/conteudo/. Acesso em: 27 maio 2017.

FRACALANZA, H. O que sabemos sobre os livros didáticos para o ensino de Ciências no Brasil. 1993. 1054f. Tese (Doutorado em Educação) - Faculdade de Educação, Universidade Estadual de Campinas, Campinas, 1993. 
GONÇALVES, R. B.; GODINHO, N. B. Práticas de pesquisa de estudantes de biblioteconomia e arquivologia: Uma abordagem sobre os aspectos afetivos envolvidos e a competência informacional. Rev. Brasileira de Educação em Ciência da Informação, v. 1, n. 1, p. 75-93, 2014.

GOODE, W. J.; HATT, P. F. Alguns problemas na análise qualitativa e na análise de caso: 1969. In: GOODE, W. J.; HATT, P. F. (org.) Métodos em pesquisa social. São Paulo: Companhia Editora Nacional, 1969. p. 398433.

HAYASHI, M. C. P. Afinidades eletivas entre a cientometria e os estudos sociais da ciência. Filosofia e Educação, São Carlos, v. 5, n. 2, p. 33-46, 2013.JESUS, L. G. de; RAZERA, J. C. C. As teorias de aprendizagem em pesquisas da área de educação em ciências: uma análise cienciométrica em periódicos brasileiros. In: CONGRESO INTERNACIONAL SOBRE INVESTIGACIÓN EN DIDÁCTICA DE LAS CIENCIAS, 9., 2013. Girona. Disponível em: http://www.raco.cat/index.php/Ensenanza/article/viewFile/307313/397287. Acesso em: 27 maio 2017.

LOURENÇO, C. A. Automação em bibliotecas: análise da produção via Biblioinfo (1986/1994). In: WITTER, G. P. (Org.). Produção científica. Campinas: Átomo, 1997. p. 25-40.

MACIAS-CHAPULA, C. A. O papel da Informetria e da cienciometria e sua perspectiva nacional e internacional. Ciência da Informação, São Carlos. v. 27, n. 2, p. 134-140, 1998.MEGID NETO, J. Três décadas de pesquisas em educação em ciências: tendências de teses e dissertações (1972 - 2003). In: NARDI, R. (Org.). A pesquisa em ensino de ciências no Brasil: alguns recortes. São Paulo: Escrituras, 2007. p. 341355.

MENEZES, E. M. Produção científica dos docentes da Universidade Federal de Santa Catarina: análise quantitativa dos anos de 1989 e 1990. 1993. Dissertação (Mestrado) - PUCCAMP - Pontifícia Universidade Católica de Campinas, Campinas, São Paulo, 1993.

NARDI, R. Memórias da Educação em Ciências no Brasil: a pesquisa em ensino de física. Investigações em Ensino de Ciências, v. 10(1), p. 63-101, 2005.

NATURE INDEX 2015. Ranking Global. Nature, United Kingdom, v. 522, n. S1, 2015.

PRITCHARD, Alan. Statistical bibliography or bibliometrics. Journal of Documentation, Bingley United Kingdom, v. 25, n. 4, p. 348-349, 1969.

PRICE, D. S. (org.). Little science, big science. Nova York: Columbia University Press, 1963. 231p.

POBLACION, D. A.; NORONHA, D. P. Produção da literatura "branca" e "cinzenta" pelos docentes/doutores dos programas de pós-graduação em ciência da informação no Brasil. Ciência da Informação, Brasília, v. 31, n. 2, p. 98-106, 2002.

QUANDT, C. O.; CRUZ, J. A. W.; ROSA, C. A.; WELGACZ, H. T. A produção científica brasileira em gestão do conhecimento: análise cienciométrica e mapeamento de redes de autores do Enegep, 1998-2008. Revista Gestão Industrial, v. 5, n. 1, 172-188, 2009. Disponível em: https://periodicos.utfpr.edu.br/revistagi/article/viewFile/486/375. Acesso em: 14 jun. 2017.

RAZERA, J. C. C. A formação de professores em artigos da revista Ciência \& Educação (1998-2014): uma revisão cienciométrica. Ciência \& Educação, Bauru, v. 22, n. 3, p. 561-583, 2016a. Disponível em: http:// www.redalyc.org/articulo.oa?id=251047415002. Acesso em: 28 jun. 2017.

RAZERA, J. C. C. Contribuições da cienciometria para a área brasileira de Educação em Ciências. Ciência \& Educação, Bauru, v. 22, n. 3, p. 557-560, set. 2016b. Disponível em: http://www.scielo.br/scielo.php?script=sci_arttext\&pid=S1516-73132016000300557\&Ing=en\&nrm=iso. Acesso em: 29 jun. 2017.

RICHARDSON, R. J. (org.). Pesquisa social: métodos e técnicas. São Paulo: Atlas, 1989.

SANTOS, R. N. M.; KOBASHI, N. Y. Bibliometria, Cientometria, Informetria: Conceitos e Aplicações. Tendências da Pesquisa Brasileira em Ciência da Informação, Brasília, v. 2, n. 1, 2009. Disponível em: http:// inseer.ibict.br/ancib/index.php/tpbci/article/view/21/43. Acesso em: 18 abr. 2017.

SAVIANI, D. Pedagogia histórico-crítica: primeiras aproximações. São Paulo: Autores Associados, 1997.

SERACEVIC, T. Ciência da informação: origem, evolução e relações. Ciência da Informação, Belo Horizonte, v. 1, n. 1, p. 41-62, 1996.

SILVA, M. R. Análise bibliométrica da produção científica docente do programa de pós-graduação em Educação Especial da UFSCar: 1998-2003. 2004. 168f. Dissertação (Mestrado) - Ufscar, Universidade Federal de São Carlos, Programa de Pós-Graduação em Educação Especial, São Carlos, 2004.

SOARES, M. B. Alfabetização no Brasil: o estado do conhecimento. Brasília: Inep; Reduc, 1989. 157 p.

SPINAK, E. Indicadores cienciométricos. Revista Ciência da Informação, Brasília, v. 27, n. 2, 1998. Disponível em: http://www.scielo.br/scielo.php?script=sci_arttext\&pid=S0100-19651998000200006. Acesso em: 20 abr. 2017. 


\section{\&Educaçăo}

Um Breve Olhar Sobre a Cienciometria:

origem, evolução, tendências e sua contribuição para o ensino de Ciências

TEIXEIRA, P. M. M.; MEGID NETO, J. Investigando a pesquisa educacional. Um estudo enfocando dissertações e teses sobre o ensino de biologia no Brasil. Investigações em Ensino de Ciências, Porto Alegre. v. 11, n. 2, p. 261-282, 2006.

VANTI, N. A. P. Da bibliometria à webometria: uma exploração conceitual dos mecanismos utilizados para medir o registro da informação e a difusão do conhecimento. Ciência da Informação, Brasília, v. 31, n. 2, 2002. Disponível em: www.scielo.br/cgi-bin/fbpe/. Acesso em: 11 maio 2017.

VELHO, L. Indicadores científicos: em busca de teoria. Interciencia, Caracas, v. 15, n. 3, p. 139-145, 1990.

VELHO, Edna. A ciência e seu público. Transinformação, Campinas, v. 9, n. 3, p. 15-32, 1997. Disponível em: www.capes.gov.br. Acesso em: 20 abr. 2017. 